\title{
Bone scintigraphy in chronic knee pain: comparison with magnetic resonance imaging
}

Torsten Boegård, Olof Rudling, Jan Dahlström, Hans Dirksen, Ingemar F Petersson, Kjell Jonsson

\begin{abstract}
Objective-To compare increased bone uptake of ${ }^{99} \mathrm{Tc}^{\mathrm{m}}$-MDP and magnetic resonance (MR) detected subchondral lesions, osteophytes, and cartilage defects in the knee in middle aged people with longstanding knee pain.

Methods-Fifty eight people (aged 41-58 years, mean 50) with chronic knee pain, with or without radiographic knee osteoarthritis, were examined with bone scintigraphy. The pattern and the grade of increased bone uptake was assessed. On the same day, a MR examination on a 1.0 T imager was performed. The presence and the grade of subchondral lesions, osteophytes, and cartilage defects were registered.

Results-The $\kappa$ values describing the correlation between increased bone uptake and MR detected subchondral lesions varied between 0.79 and 0.49 , and between increased bone uptake and MR detected osteophytes or cartilage defects the values were $<0.54$. The $\kappa$ values describing the correlation between the grade of bone uptake and the grade of the different MR findings was $<0.57$.
\end{abstract}

Conclusions-Good agreement was found between increased bone uptake and MR detected subchondral lesion. The agreement between increased bone uptake and osteophytes or cartilage defects was in general poor as well as the agreement between the grade of bone uptake and the grade of the MR findings.

(Ann Rheum Dis 1999;58:20-26)

Osteoarthritis (OA) is a multifactorial process ${ }^{1}$ affecting cartilage and subchondral bone. ${ }^{2}$ Radiographic OA of the knee joint is a common disorder. In European populations prevalence values for radiographic $\mathrm{OA}$ of the tibiofemoral joint (TFJ) range from $1 \%(35-54 \text { years })^{3}$ to between 40 and $60 \%$ in older age groups (75-79 years). ${ }^{4}$ Recent data suggest that OA of the patellofemoral joint (PFJ) is an important cause of pain and disability ${ }^{5}$ and in a population based study of middle aged women $(n=325$, mean age 59 years) $6 \%$ had OA of TFJ, $13 \%$ OA of the PFJ, and $15 \%$ involvement of both joints. ${ }^{6}$ The disease is currently diagnosed by clinical or radiographic criteria, or both, which only allow detection of fairly advanced stages of the disease process.?

Bone scintigraphy is used to detect changed bone metabolism ${ }^{8}$ and has proved to be a more sensitive diagnostic modality in comparison with radiography and arthrography in a com- partmental evaluation of knee OA. ${ }^{9}$ In an animal model with OA the radionuclide uptake was localised to growing osteophytes in the early stage of the disease and in the late stage localised to subchondral bone under denuded or eburnated articular surfaces. ${ }^{10}$ Thus the method provides a potential to assess important aspects of the disease. An abnormal bone scintigraphy in radiographically normal hands is a predictor of subsequent radiographic change. ${ }^{11}{ }^{12}$ In a study of knee OA no patients with normal bone scintigraphy had radiographic progression at follow up five years later. ${ }^{13}$ Bone scintigraphic changes also correlate to serum markers of cartilage and bone metabolism between people with or without radiographic OA. ${ }^{14}$

Magnetic resonance (MR) imaging with its good tissue contrast and anatomical resolution provides a non-invasive examination tool of the TFJ in early stages of OA, for detection of cartilage defects ${ }^{15}$ and is a sensitive means in detecting bone marrow lesions. ${ }^{16-18}$

Only few studies ${ }^{19}$ have compared bone scintigraphy and MR imaging. The potential of bone scintigraphy to assess different aspects of the OA process ${ }^{10}$ and to predict its progres$\operatorname{sion}^{12}{ }^{13}$ have been established. These aspects have encouraged us to use bone scintigraphy in addition to plain radiographs and MR imaging in a selected group of middle aged people with chronic knee pain for prospective follow up. The aim of our study was to compare increased bone uptake of technetium $99 \mathrm{~m}$ labelled methylene diphosphonate $\left({ }^{99} \mathrm{Tc}^{\mathrm{m}}-\mathrm{MDP}\right)$ in the TFJ and the PFJ with MR detected subchondral lesions, osteophytes, and cartilage defects in the same joint of these people.

\section{Methods}

SUBJECTS

To create a cohort of people with chronic knee pain (defined as duration $>3$ months at inclusion) for prospective follow up, an epidemiological survey of 2000 persons aged 35-54 years in a rural area in southern Sweden was performed. ${ }^{3}$ Chronic knee pain was reported by 279 of 2000 and 204 of 279 accepted to be examined clinically, biochemically, and radiographically at baseline 1990-91. Thirteen of the 204 subjects had arthritides other than OA and six had chronic knee pain resulting from a defined knee trauma. In the remaining 185 cases no obvious cause of chronic knee pain was found. All were examined with posteroanterior radiographs with straight knees in standing position of the TFJ, with the weight equally distributed on both legs. Before the 


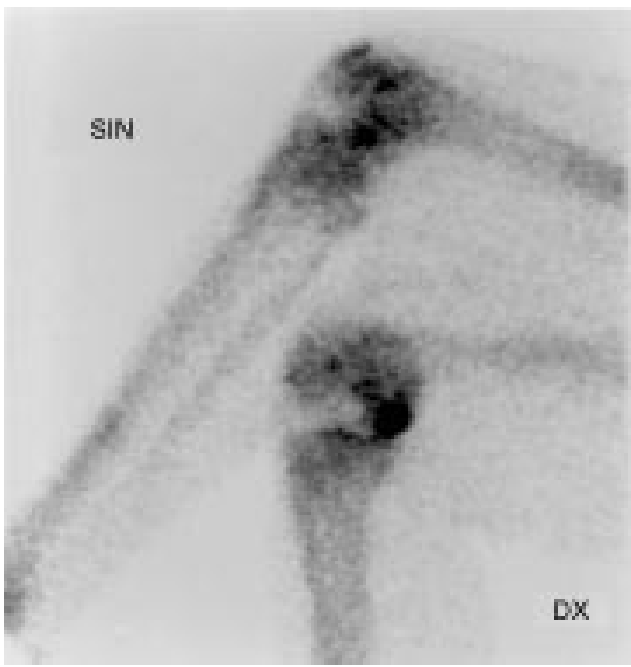

Figure 1 Bone scintigram of the knees in right medial and left lateral projection in a 51 year old woman, showing an increased bone uptake with a point-like pattern of grade 2 in the medial femoral condyle of the right knee (the signal knee). The left knee has normal uptake.

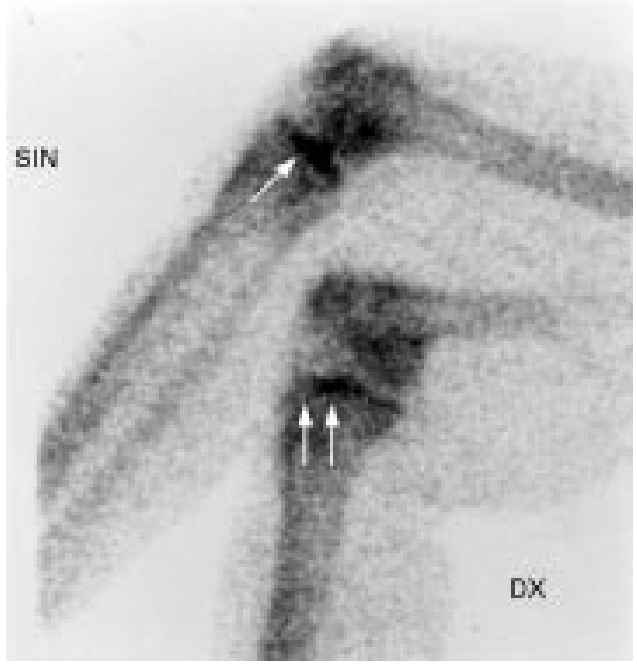

Figure 2 Bone scintigram of the knees in right medial and left lateral projection in a 58 year old woman,

demonstrating an increased bone uptake with a tramline pattern of grade 1 in the lateral tibial condyle of the left knee (arrow) (the signal knee) as well as in the medial tibial condyle of the right knee (double arrow).

three year follow up another two people were excluded, according to the exclusion criteria above, leaving 183 subjects. At the three year follow up a subgroup of 61 subjects (61 of 183) were chosen as a random sample from the initial cohort after exclusion of those having severe OA with obliteration of joint space or bone attrition at the baseline examination. All 61 subjects had a scintigraphic examination of both knees and 59 subjects a diagnostic MR study of the signal knee (defined as the most painful at inclusion). The MR study was not performed in one patient because of claustrophobia and in another patient because of tremor caused by Parkinson's disease. Yet another patient had an extensive bone uptake in the proximal tibia of the signal knee because of a high tibial osteotomi, which made it impossible to evaluate this region of the knee and the knee was excluded. Thus 58 of 61 knees were included in the study representing 29 women (mean age 50.4 years, 42-58) and 29 men (mean age 49.5 years, 41-57). The scintigraphic and the MR examination were performed on the same day in each patient.

SCINTIGRAPHIC METHOD

The amount of $370 \mathrm{MBq}{ }^{99} \mathrm{Tc}^{\mathrm{m}}-\mathrm{MDP}$ was injected intravenously. Immediately after the injection of the radionuclide, an early phase (perfusion phase) scan was recorded as 80 five seconds frames in an anterior projection, using a general purpose collimator. The bone uptake was recorded after four hours as three, five minutes frames in anterior, medial, and lateral projections for both knees using a high resolution collimator (Toshiba gammacamera, GCA901-A). The matrix size was $256 \times 256$. The examinations were visually evaluated in blind and separately by two of the authors (HD, JD), both experienced in bone scintigraphy, who then reached a consensus. The increased uptake in each knee was graded as generalised or localised using a 4 point scale $(0=$ normal, 1 =light, 2 =moderate, and 3 =severe). The localised bone uptake was graded separately for each condyle of the TFJ, the patella, and the femoral trochlea. With some modifications according to $\mathrm{McCrae} e t a l^{0}$ three different patterns of localised radionuclide uptake were recognised; point-like (fig 1), tramline (fig 2), and extended (fig 3). In this study only the results in the signal knees are reported.

\section{MR EXAMINATION}

MR imaging was performed in the signal knee with a $1.0 \mathrm{~T}$ imager (Impact, Siemens) with a circular polarised surface coil. The initial six patients were examined with a coronal T1 weighted spin echo sequence, a sagittal proton density and T2 weighted turbo spin echo sequence (tSEPdT2), a 3D gradient echo

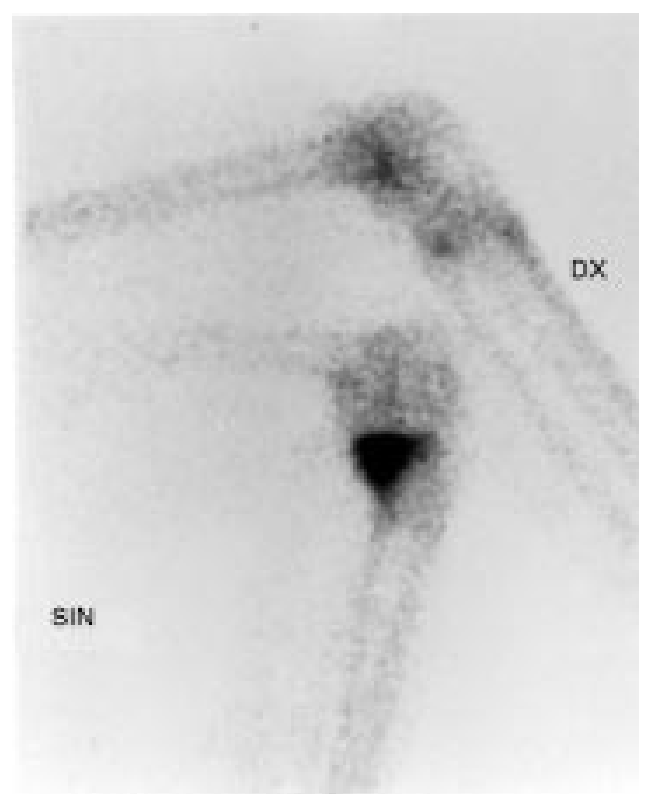

Figure 3 Bone scintigram of the knees in right lateral and left medial projections in a 42 year old woman, showing an increased bone uptake with an extended pattern in the medial tibial condyle of the left knee (the signal knee). The right knee has normal uptake. 

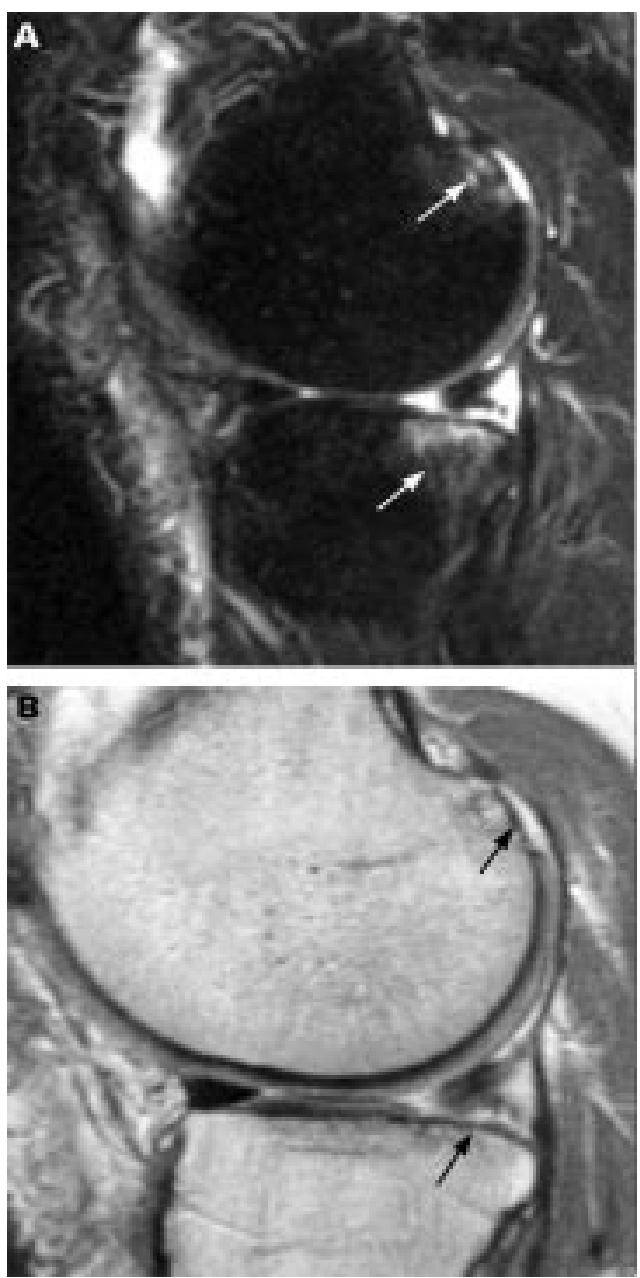

Figure 4 (A) A sagittal T2 weighted STIR+MR image of the right knee in a 43 year old man demonstrating a subchondral lesion of grade 2 dorsal in the lateral femoral condyle as well as in the lateral tibial condyle (arrows). (B) In a corresponding sagittal proton density weighted $M R$ image is shown adjacent cartilage defects of grade $2 \mathrm{in}$ both locations (arrows).

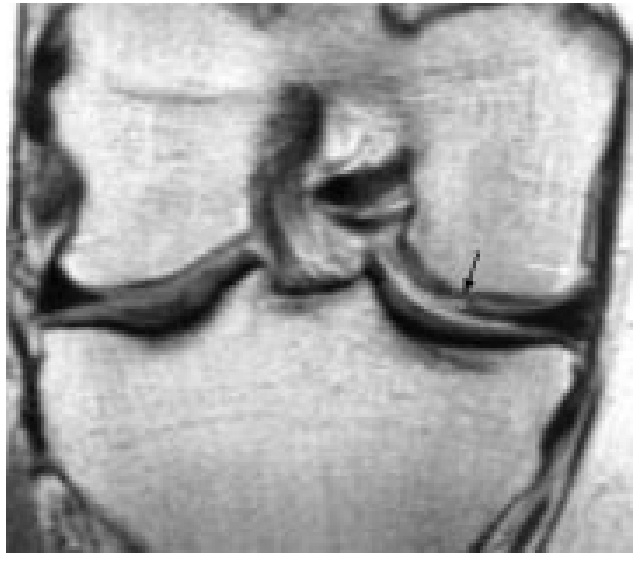

Figure $5 A$ coronal proton density weighted MR image of the right knee in a 57 year old woman demonstrating a peripheral osteophyte of grade 1, at the medial femoral condyle (white arrow). Note the cartilage defect of grade 2 in the same condyle (black arrow).

sequence (Dess), and a sagittal 2D gradient echo. The last patient in this group was also examined with a T2 weighted short tau inversion recovery sequence (tT2STIR) in the sagittal view. The remaining patients were examined with a tSEPdT2 sequence in the coronal, sagittal, and axial views and a tT2STIR sequence in the sagittal view. The sagittal sequence was perpendicular to a line connecting the dorsal aspects of the femoral condyles, the coronal sequence was parallel to that line, and the axial sequence was perpendicular to the long axis of the patella. The sequence parameters for the tSEPdT2 were: TR/TE 4200/15-105 ms with two signals averaged, echo train length 7 , FOV $145 \times 145 \mathrm{~mm}$, section thickness $3 \mathrm{~mm}$ with $0.3-0.6 \mathrm{~mm}$ intersection gap, matrix size $252 \times 256$, and acquisition time $5 \mathrm{~min} 8 \mathrm{~s}$. The parameters for the tT2STIR sequence were: TR/TE 4900/60 ms with two signals averaged, echo train length 11, TI $150 \mathrm{~ms}$, FOV $200 \times 200 \mathrm{~mm}$, section thickness $4 \mathrm{~mm}$, intersection gap $0.8 \mathrm{~mm}$, matrix size $242 \times 256$, and acquisition time 3 $\min 40 \mathrm{~s}$.

The MR examinations were assessed for subchondral lesions, peripheral osteophytes, and cartilage defects in/at each of the articular surfaces of the TFJ and the PFJ.

Subchondral lesions with increased signal in the tT2STIR sequence (fig 4A) in the immediate vicinity of the joint cartilage in each articular surface (for instance the medial femoral condyle) were measured by a ruler, and classified according to their greatest diameter as grade $1(<1 \mathrm{~cm})$, grade $2(\geqslant 1-<2 \mathrm{~cm})$, and grade $3(\geqslant 2 \mathrm{~cm})$. If there were two or more lesions adjacent to an articular surface the largest lesion was measured.

The greatest perpendicular length from the cortical bone to the outer margin of the largest marginal osteophyte (fig 5) at each articular surface was measured by a ruler and classified as grade $1(<2.5 \mathrm{~mm})$, grade $2(\geqslant 2.5-<5 \mathrm{~mm})$, grade $3(\geqslant 5-<10 \mathrm{~mm})$, and grade $4(\geqslant 10$ $\mathrm{mm})$. Osteophytes at the tibial eminence were not considered.

The tSEPd sequence was mainly used to grade the cartilage defects and sometimes in addition with the tSET2 sequence to exploit its more pronounced arthrographic effect. Cartilage defects (fig 4B and fig 5 ) in each articular surface were classified as grade $1, \leqslant 50 \%$ reduction of the cartilage thickness, as grade 2 , $>50 \%$ reduction of the cartilage thickness, and as grade 3, cartilage defect with bone loss. ${ }^{21} 22$ Signal changes of the cartilage with an intact surface were not registered.

The MR studies were interpreted blindly and separately by two of the authors (TB, OR) with experience in musculoskeletal MR imaging, who then reached a consensus.

After the initial and separate evaluations of the scintigraphic and the MR examinations both studies in each patient were compared by three of the authors (TB, HD, JD).

The study was approved by the Committee on Ethics at the Faculty of Medicine, University of Lund.

\section{STATISTICAL ANALYSES}

The McNemar test was used to compare the number of increased bone uptakes between the TFJ and the PFJ, and between the patella and the femoral trochlea. The test was also 
Table 1 Pattern and location of increased bone uptake in 30 knees

\begin{tabular}{lcccc}
\hline Location & Point-like & Tramline & Extended & Total \\
\hline Medial tibia & 5 & 11 & 1 & 17 \\
Medial femur & 4 & 3 & 2 & 9 \\
Lateral tibia & 1 & 5 & 1 & 7 \\
Lateral femur & 0 & 2 & 3 & 5 \\
Patella & 5 & 1 & 7 & 13 \\
Femoral trochlea & 3 & 1 & 1 & 5 \\
Total & 18 & 23 & 15 & 56 \\
\hline
\end{tabular}

performed with six contingency tables in which the number of bone uptakes in the different surfaces of the TFJ were compared with each other.

The measure used to assess the correlation between increased bone uptake and MR detected subchondral lesions, cartilage defects or osteophytes was $\kappa .^{23} \mathrm{~A} \kappa$ value of $1.00-0.81$ was considered as very good, $0.80-0.61$ as good, $0.60-0.41$ as moderate, $0.40-0.21$ as fair, and $0.20-0.00$ as poor. ${ }^{23}$

\section{Results}

An abnormal scintigraphic perfusion phase was seen in four knees $(7 \%)$. The increased activity was general in three knees, all with obliteration of the joint space in medial TF compartment and was confined to the patella in one knee, probably because of a prepatellar bursitis detected by MR imaging.

Fifty eight locations with increased bone uptake were identified in 32 knees (55\%). When the scintigraphic and the MR studies were compared two bone uptakes were found to be caused by patella partita. One uptake had a tramline pattern and the other a point-like pattern and both uptakes were of grade 1 . These two bone uptakes were excluded, leaving 56 increased bone uptakes in 30 knees (52\%) for the comparison. Table 1 lists the pattern and the location of the bone uptakes. The TFJ was affected in 20 subjects (34\%) and the PFJ in $14(24 \%)$. Thirteen increased bone uptakes were of grade 2 and two bone uptakes were of grade 3. In two knees increased bone uptake was identified in all evaluated locations. No generalised increased bone uptake was found. In the TFJ 12 subjects had isolated medial

Table 2 MR findings in 52 knees. In each location the findings are broken down in grades $(G r)$

\begin{tabular}{|c|c|c|c|c|c|c|}
\hline$\frac{\text { Location }}{\text { Medial tibia }}$ & \multicolumn{2}{|c|}{ Subchondral lesions } & \multicolumn{2}{|c|}{ Osteophytes } & \multicolumn{2}{|c|}{ Cartilage defects } \\
\hline Medial tibia & 9 & $\begin{array}{l}\text { Gr } 1=3 \\
\text { Gr } 2=2 \\
\text { Gr } 3=4\end{array}$ & 25 & $\begin{array}{l}\text { Gr } 1=15 \\
\text { Gr } 2=8 \\
\text { Gr } 3=1 \\
\text { Gr } 4=1\end{array}$ & 11 & $\begin{array}{l}\text { Gr } 1=2 \\
\text { Gr 2=6 } \\
\text { Gr } 3=3\end{array}$ \\
\hline Medial femur & 8 & $\begin{array}{l}\text { Gr } 1=5 \\
\text { Gr } 2=1 \\
\text { Gr } 3=2\end{array}$ & 18 & $\begin{array}{l}\text { Gr } 1=9 \\
\text { Gr 2=5 } \\
\text { Gr 3=3 } \\
\text { Gr } 4=1\end{array}$ & 24 & $\begin{array}{l}\text { Gr } 1=6 \\
\text { Gr } 2=14 \\
\text { Gr } 3=4\end{array}$ \\
\hline Lateral tibia & 3 & $\begin{array}{l}\text { Gr } 1=2 \\
\text { Gr } 2=1\end{array}$ & 20 & $\begin{array}{l}\text { Gr } 1=16 \\
\text { Gr } 2=2 \\
\text { Gr } 3=2\end{array}$ & 9 & $\begin{array}{l}\text { Gr } 1=3 \\
\text { Gr } 2=5 \\
\text { Gr } 3=1\end{array}$ \\
\hline Lateral femur & 4 & $\begin{array}{l}\text { Gr } 1=2 \\
\text { Gr } 2=1 \\
\text { Gr } 3=1\end{array}$ & 15 & $\begin{array}{l}\text { Gr } 1=8 \\
\text { Gr 2=5 } \\
\text { Gr 3 }=2\end{array}$ & 11 & $\begin{array}{l}\text { Gr } 1=4 \\
\text { Gr } 2=5 \\
\text { Gr } 3=2\end{array}$ \\
\hline Patella & 5 & $\begin{array}{l}\text { Gr } 1=2 \\
\text { Gr } 2=2 \\
\text { Gr } 3=1\end{array}$ & 25 & $\begin{array}{l}\text { Gr } 1=20 \\
\text { Gr 2 }=3 \\
\text { Gr 3 }=2\end{array}$ & 40 & $\begin{array}{l}\text { Gr } 1=15 \\
\text { Gr } 2=25\end{array}$ \\
\hline Femoral trochlea & 4 & $\begin{array}{l}\text { Gr } 1=1 \\
\text { Gr } 2=3\end{array}$ & 14 & $\begin{array}{l}\text { Gr } 1=11 \\
\text { Gr } 2=1 \\
\text { Gr } 3=1 \\
\text { Gr } 4=1\end{array}$ & 22 & $\begin{array}{l}\text { Gr } 1=13 \\
\text { Gr } 2=9\end{array}$ \\
\hline Total & 33 & & 117 & & 117 & \\
\hline
\end{tabular}

Table 3 The $\kappa$ values describing the correlation between increased bone uptakes and MR detected subchondral lesions, osteophytes, and cartilage defects

\begin{tabular}{llll}
\hline & $\begin{array}{l}\text { Bone uptakel } \\
\text { subchondral } \\
\text { lesion }\end{array}$ & $\begin{array}{l}\text { Bone } \\
\text { uptake/ } \\
\text { osteophyte }\end{array}$ & $\begin{array}{l}\text { Bone } \\
\text { uptake/ } \\
\text { cartilage } \\
\text { defect }\end{array}$ \\
\hline Medial tibia & 0.52 & 0.20 & 0.54 \\
Medial femur & 0.79 & 0.30 & 0.26 \\
Lateral tibia & 0.59 & 0.14 & 0.42 \\
Lateral femur & 0.64 & 0.31 & 0.15 \\
Patella & 0.49 & 0.03 & 0.06 \\
Femoral trochlea & 0.64 & 0.10 & 0.18 \\
\hline
\end{tabular}

compartment and one subject isolated lateral compartment increased bone uptake and in seven subjects there were combined medial and lateral bone uptake. Increased bone uptake was more common in the medial than in the lateral compartment of the TFJ $(\mathrm{p}<0.01)$. It was also more common in the medial tibial condyle as compared with the medial femoral condyle $(\mathrm{p}<0.05)$ and in the patella as compared with the femoral trochlea $(\mathrm{p}<0.05)$.

Thirty three MR detected subchondral lesions were found in 21 knees (36\%) (table 2). The TFJ was affected in 15 knees $(26 \%)$ and the PFJ in eight knees (14\%). Ten lesions of grade 2 and seven lesions of grade 3 were found. Three or more locations with subchondral lesions in the same knee were seen in three subjects.

One hundred and seventeen MR detected marginal osteophytes were seen in 37 knees $(64 \%)$ (table 2). The TFJ was affected in 32 knees (55\%) and the PFJ in 28 knees (48\%). Twenty four osteophytes of grade 2 were found as well as 11 osteophytes of grade 3 and three osteophytes of grade 4. Marginal osteophytes at the medial tibial condyle were more frequent as compared with the medial femoral condyle $(\mathrm{p}<0.05)$ and as compared with the lateral femoral condyle $(p<0.01)$. Osteophytes were also more frequent at the patella than at the femoral trochlea $(\mathrm{p}<0.01)$.

One hundred and seventeen MR detected cartilage defects were registered in 51 knees (88\%) (table 2). The TFJ was affected in 34 of these knees (59\%) and the PFJ in 41 knees (71\%). Defects of grade 3 (attrition) were seen in 10 joint surfaces in five TFJ. There were more cartilage defects in the medial femoral condyle than in the other condyles of the TFJ $(p<0.01)$ and in the patella as compared with the femoral trochlea $(\mathrm{p}<0.001)$.

In six knees $(10 \%)$ neither an increased bone uptake nor any MR abnormalities were found.

Twenty nine $(88 \%)$ of 33 subchondral lesions, $32(27 \%)$ of 117 osteophytes, and 34

Table 4 Increased bone uptake associated or not with MR detected subchondral lesion in the same location in 33 knees

\begin{tabular}{lccc}
\hline & $\begin{array}{l}\text { Bone uptake } \\
\text { with } \\
\text { subchondral } \\
\text { lesion }\end{array}$ & $\begin{array}{l}\text { Bone uptake } \\
\text { without } \\
\text { subchondral } \\
\text { lesion }\end{array}$ & Total \\
\hline Mecation & 8 & 9 & 17 \\
Medial tibia & 7 & 2 & 9 \\
Lateral tibia & 3 & 4 & 7 \\
Lateral femur & 3 & 2 & 5 \\
Patella & 5 & 8 & 13 \\
Femoral trochlea & 3 & 2 & 5 \\
Total & 29 & 27 & 56 \\
\hline
\end{tabular}


Table 5 The relation between increased bone uptake in locations without MR detected subchondral lesion to MR detected cartilage defects and/or osteophytes in 18 knees

\begin{tabular}{lllccc}
\hline & $\begin{array}{l}\text { Cartilage } \\
\text { defect }+ \\
\text { osteophyte }\end{array}$ & $\begin{array}{l}\text { Cartilage } \\
\text { defect }\end{array}$ & Osteophyte & No lesion & Total \\
\hline Location & - & 1 & 3 & 5 & 9 \\
\hline Medial tibia & - & - & - & 2 & 2 \\
Medial femur & - & - & - & 2 & 4 \\
Lateral tibia & - & - & 1 & 1 & 8 \\
Lateral femur & 1 & 1 & - & -11 & 2 \\
Patella & 3 & 8 & 5 & & 27 \\
Femoral trochlea & & & & & \\
\hline
\end{tabular}

(29\%) of 117 cartilage defects were associated with an increased bone uptake in the same location.

Table 3 lists the correlations between increased bone uptakes and MR detected subchondral lesions, osteophytes, and cartilage defects. The $\kappa$ values describing the correlation between the grade of bone uptake and the grade of MR detected subchondral lesions was for the medial femur 0.48, the lateral tibia 0.57, and the lateral femur 0.41 . The $\kappa$ values of all other correlations between the grade of increased bone uptakes and the grade of $M R$ findings was $<0.31$.

Table 4 shows the location of increased bone uptake associated or not with MR detected subchondral lesion. Four of 33 subchondral lesions were not associated with increased bone uptake. One of these was not found at the comparison between the scintigraphic and the MR examinations and the other three lesions were of grade 1 . In the patella seven of eight increased bone uptakes, which did not correspond to MR detected subchondral lesions, were of the extended pattern, while the other lesions in the patella had a point-like or a tramline pattern. Table 5 lists the relation between increased bone uptake, in locations without MR detected subchondral lesion, MR detected cartilage defects and/or osteophytes.

\section{Discussion}

A previous study has compared the findings of MR imaging and bone scintigraphy in patients with radiographically advanced knee OA. ${ }^{19}$ In the signal knee of our cohort only 16 of 59 had joint space narrowing (JSN) $(<3 \mathrm{~mm})$ in the $\mathrm{TFJ}^{21}$ and 21 of $57 \mathrm{had}$ JSN $(<5 \mathrm{~mm})$ in the PFJ. ${ }^{22}$ An early generalised increased uptake (perfusion phase), indicative for synovitis ${ }^{24}$ was seen in three knees only. A late generalised increased uptake, which strongly correlates with joint pain and osteophytes, ${ }^{20}$ was not seen in our patients. These findings thus indicate that the OA process was less advanced in our group of patients and they were also younger.

The different patterns of increased bone uptake described by McCrae et al, ${ }^{20}$ were with some modifications used in this study and they were easy to apply. The term hot patella was changed to the term extended pattern and the term point-like pattern was introduced. In agreement with previous findings, ${ }^{20}$ joint line scan abnormalities (point-like and tramline pattern) were far more common in the TFJ than the extended pattern.

As reported by others ${ }^{19} 2025$ the increased bone uptake were more common in the medial compartment than in the lateral compartment of the TFJ, which is in agreement with the fact that radiographic OA of the TFJ is predominantly a medial disorder. ${ }^{2126}$ Combined increased bone uptake in the medial and the lateral compartment was common in our study but not to the same extent as in a study of patients with severe OA. ${ }^{9}$

MR imaging is considered to be an accurate means especially for detecting and staging moderate and advanced cartilage lesions in the $\mathrm{TFJ}^{27}{ }^{28}$ and in the PFJ, ${ }^{27} 2930$ while superficial lesions are detected with less sensitivity. The fast spin echo $2 \mathrm{D}$ sequence used in this study does not differ in this respect and has also been used by others. ${ }^{31}{ }^{32}$ The reason why we did not pursue with the $3 \mathrm{D}$ gradient echo (Dess) was that reconstruction in coronal and axial planes was of inferior quality to evaluate hyaline cartilage. The examination time was considerably longer than the tPdT2SE sequence, which gives an increased risk of motion artefacts. The examination quality of the initial six patients was considered equal and they have therefore been included in the study. According to recent results it seems that high resolution $\mathrm{T} 1$ weighted 3D gradient echo sequences with the addition of fat suppression or magnetisation transfer contrast are the best for depicting hyaline cartilage. ${ }^{33-36}$ As mentioned above the $3 \mathrm{D}$ gradient echo sequences has a long acquisition time with potential disadvantages.

MR imaging is also a sensitive means for detecting bone marrow lesions and has rapidly become the preferred imaging technique to determine the presence and extent of these lesions. ${ }^{16} \mathrm{~T} 1$ weighted, fat saturation $\mathrm{T} 2$ weighted, and STIR sequences all provide a high degree of sensitivity for depiction of most types of bone marrow abnormalities. ${ }^{16}$ We have used tT2STIR sequence to depict subchondral lesions, to assess the presence and extent of subchondral bone involvement of the OA process. This turbo sequence can provide STIR images much more rapidly than the conventional sequence without compromising image quality or lesion detection. ${ }^{17}{ }^{18}$ In the initial five patients the tT2STIR sequence was not performed. We feel that the sagittal $2 \mathrm{D}$ gradient echo and the $3 \mathrm{D}$ gradient echo obtained in the sagittal plane used in these patients were very sensitive for subchondral lesions, especially when they also were possible to compare with the T1 weighted spin echo sequence in the coronal plane and the tSEPdT2 sequence in the sagittal plane performed in these patients. The only potential drawback was the uncertainty of measuring the diameter of each particular lesion.

The STIR sequence has been used by others, ${ }^{19}$ to detect subchondral lesions in the TFJ and in the PFJ in knee OA. As has been suggested ${ }^{19}$ the subchondral lesions could represent synovial leak, inflammation or presence of fibrovascular tissue. In our study subchondral lesions of the TFJ and the PFJ were predominantly in the medial TF compartment and in the patella respectively. In the patella six of seven increased bone uptakes of the extended pattern (hot patella) did not correspond to a subchondral lesion, while five of six 
uptakes in the patella with a point-like or tramline pattern corresponded to such a lesion. Thus it seems that the latter pattern of increased bone uptake is more associated with subchondral lesions in the patella. In two of the cases with an extended bone uptake in the patella we found a high signal on the T2 weighted sequence in the soft tissue adjacent to the anterior aspect to the patella, possibly because of a local inflammatory disorder (prepatellar bursitis?). In young adults a relation between anterior knee pain and an extended pattern of increased bone uptake in the patella has been found. ${ }^{37}$

A correlation between increased bone uptake and subchondral lesion was found. The correlation was good in the medial femur, in the lateral femur, and in the femoral trochlea. The correlation was moderate in the medial tibia, in the lateral tibia, and in the patella. Twenty nine of 33 subchondral lesions were combined with an increased bone uptake. Maybe these lesions represent a later stage in the $\mathrm{OA}$ process according to Christensen. ${ }^{10} \mathrm{He}$ found increased bone uptake localised to subchondral bone under denuded or eburnated articular surfaces in the late stage of the disease in an animal model with OA, while the bone uptake was localised to osteophytes in the early stage of the disease. The increased bone uptake reflects an ongoing bone reaction and as a relation was found between the increased bone uptake and the subchondral lesion, the latter will also represent a current bone reaction.

Osteophytes and cartilage defects were common MR findings in the TFJ as well as in the PFJ. In the study by McAlindon et a $l^{19}$ cartilage thinning had an unexpected low prevalence, 5 of 12 knees, while cartilage defects in our study of early OA, were found in 52 of 59 knees. This difference between the studies probably reflects the improved resolution in the standard MR sequences, because of the rapid progress of the MR technique, both in hardware and in software.

All osteophytes in our study had as high signal on $\mathrm{Pd}$ and $\mathrm{T} 2$ weighted turbo spin echo sequences as normal bone marrow fat and thus resemble "hyperintense osteophytosis" described by McAlindon et al. ${ }^{19}$ But these sequences without fat suppresion offer poor contrast between free water and fat. Therefore osteophytes filled with either bone marrow fat or bone marrow oedema appear bright in these sequences. In the STIR sequence that nulls fat signal the marrow oedema appears bright.

The correlation between increased bone uptakes and osteophytes and between uptakes and cartilage defects was fair or poor except for cartilage defects in the medial and lateral tibia. The increased bone uptake reflects an ongoing bone reaction and the osteophyte identified on MR imaging is a record of what has happened and thus explains the poor relation between bone uptake and osteophyte. ${ }^{9}$ Furthermore the correlation between the grade of increased bone uptakes and the grade of osteophytes was fair or poor.

A strong relation between marginal osteophytes and cartilage lesions has been found in experimentally induced knee OA in dogs, in which osteophytes appear early in the course of the disease. ${ }^{38} 39$ In another animal model with $\mathrm{OA}$, the radionuclide uptake was localised to growing osteophytes in the early stage of the disease. ${ }^{10}$ Thus, increased bone uptake without corresponding subchondral lesion found in our study probably represents a growing osteophyte. Such an osteophyte is not necessarily a predictor of OA progression in the TFJ, defined as radiographically appearing structural changes, but osteophytes grow at a higher rate in cases with structural changes or in cases who later will develop such changes. ${ }^{40}$

We are well aware of the disadvantages of the cross sectional design of the study, but we found our results interesting to present. The question of changes over time have to be considered in follow up studies. Are the patterns and gradings of the increased bone uptake clinically relevant, as well as the gradings of subchondral lesions, cartilage defects, and marginal osteophytes? The significance of different grades in these lesions is not yet known and these questions have also to be investigated in follow up studies.

In conclusion, there was a good or moderate correlation between increased bone uptakes and MR detected subchondral lesions. The correlation was in general fair or poor between increased bone uptakes and MR detected osteophytes and cartilage defects. Further studies have to be done to evaluate if MR imaging has the same ability as bone scintigraphy to predict the progression of the OA process. This study was supported by grants from the Thelma Zoégas
Foundation, the Stig och Ragna Gorthon Foundation and ReuFoundation, the Stig och Ragna Gorthon Foundation and Reu-
matikerförbundet. We are grateful to Göran Ejlertsson for matikerforbundet. We

1 Dieppe P. Osteoarthritis: clinical and research perspective. Br J Rheumatol. 1991;30 (suppl 1):1-4.

2 Bullough PG. The patophysiology of osteoarthritis. In: RusBullough PG. The patophysiology of osteoarthritis. In: Rus-
sell RGG, Dieppe PA, eds. Osteoarthritis: current research sell RGG, Dieppe PA, eds. Osteoarthritis: current research and prospects for pharmacological

3 Petersson IF, Boegård T, Saxne T, Silman AJ, Svensson B. Radiographic osteoarthritis of the knee classified by the Ahlbäck and Kellgren and Lawrence systems for the tibiofemoral joint in people aged 35-54 years with chronic knee pain. Ann Rheum Dis 1997;56:493-6.

4 Bagge E, Bjelle A, Svanborg A. Radiographic osteoarthritis in the elderly. A cohort comparison and a longitudinal study of the "70-year old people in Göteborg". Clin Rheumatol 1992;11:486-91

5 McAlindon TE, Snow S, Cooper C, Dieppe PA. Radiographic patterns of osteoarthritis of the knee joint in the community. The importance of the patellofemoral joint. Ann Rheum Dis 1992;51:844-9.

6 Cicuttini FM, Spector T, Baker J. Risk factors for osteoarthritis in the tibiofemoral and the patellofemoral joints of the knee. J Rheumatol 1997;24:1164-7.

7 Dieppe P. Osteoarthritis and molecular markers. A rheumatologist's perspective. In: Heinegår D, Lohmander S,
Saxne T, eds. Molecular markers for joint and skeletal disSaxne T, eds. Molecular markers for joint and skeletal

eases. Acta Orthop Scand 1995;60 (suppl 266): $1-5$.
8 Francis MD, Fogelman I. ${ }^{99 \mathrm{~m}}$ Tc Diphosphonate uptake mechanism on bone. In: Fogelman I, ed. Bone scanning in clinical practice. Berlin: Springer-Verlag, 1987:7-17.

9 Thomas RH, Resnick D, Alazraki NP, Daniel D, Greenfield R. Compartmental evaluation of osteoarthritis of the knee: A comparative study of available diagnostic modalities. Radiology 1975;116:585-94.

10 Christensen SB. Localization of bone seeking agents in developing, experimentally induced osteoarthritis in the knee joint of the rabbit. Scand J Rheumatol 1983;12: 343-9.

11 Hutton CW, Higgs ER, Jackson PC, Watt I, Dieppe PA. ${ }^{99 \mathrm{~m}} \mathrm{Tc}$ HMDP bone scanning in generalised arthritis. I. Comparison of the standard radiograph and four hour bone scan son of the standard radiograph and four hour bone
image of the hand. Ann Rheum Dis 1986;45:617-21.

12 Hutton CW, Higgs ER, Jackson PC, Watt I, Dieppe PA ${ }_{99 \mathrm{~m}}$ Tc HMDP bone scanning in generalised arthritis. II. The four hour bone scan image predicts radiographic The four hour bone scan image predicts
change. Ann Rheum Dis 1986;45:622-6. 
13 Dieppe P, Cushnaghan J, Young P, Kirwan J. Prediction of the progression of joint space narrowing in osteoarthritis of 557-63.

14 Petersson IF, Boegård T, Heinegård D, Dahlström J, Svensson B, Saxne T. Bone scan and serum markers of bone and cartilage in patients with knee pain and osteoarthritis. Osteoarthritis Cartilage 1998;6:33-9.

15 Peterfy CG. MR imaging. In: Bird HA, Dougados M, eds. Imaging techniques. Part II: modern methods. Baillieres Clin Rheumatol 1996;10:635-78.

16 Mirowitz SA, Apicella P, Reinus WR, Hammerman AM. MR imaging of bone marrow lesions: relative conspicuousness on T1-weighted, fat-suppressed T2-weighted, and STIR-images. AJR 1994;162:215-21.

17 Smith RC, Constable RT, Reinhold C, McCauley T, Lange RC, McCarthy S. Fast spin echo STIR imaging. J Comput Assist Tomogr 1994;18:209-13.

18 Hilfiker P, Zanetti M, Debatin JF, McKinnon G, Hodler J. Fast spin-echo inversion-recovery imaging versus fast T2-weighted spin-echo imaging in bone marrow abnorT2-weighted spin-echo imaging in bone
malities. Invest Radiol 1995;30:110-14.

19 McAlindon TEM, Watt I, McCrae F, Goddard P, Dieppe PA. Magnetic resonance imaging in osteoarthritis of the knee: Correlation with radiographic and scintigraphic findings. Ann Rheum Dis 1991;50:14-19.

20 McCrae F, Shouls J, Dieppe P, Watt I. Scintigraphic assessment of osteoarthritis of the knee joint. Ann Rheum Dis 1992;51:938-42.

21 Boegård T, Rudling $\mathrm{O}$, Petersson IF, Sanfridsson J, Saxne T, Svensson B, et al. Postero-anterior radiogram of the knee in weight-bearing and semiflexion. Comparison with MR imaging. Acta Radiol 1997;38:1063-70.

22 Boegård T, Rudling $\mathrm{O}$, Petersson IF, Sanfridsson J, Saxne T, Svensson B, et al. Joint-space width in the axial view of the patello-femoral joint. Definitions and comparison with MR imaging. Acta Radiol 1998;39:24-31.

23 Altman DG. Practical statistics for medical research. London: Chapman and Hall, 1991.

24 McCrae FC, Palmer M, Shouls J C, Watt I, Dieppe P. Scintigraphic assessment of synovial and bone responses after tigraphic assessment of synovial and bone responses after
intra-articular yttrium intra-articular yttrium ${ }^{90}$ the

25 Egund N, Frost S, Brismar J, Gustafsson T. Radiography and scintigraphy in the assessment of early gonarthrosis. Acta Radiol 1988;29:451-5.

26 Ahlbäck S. Osteoarthrosis of the knee. A radiographic investigation. Acta Radiol 1968;suppl 277:7-72.

27 Heron CW, Calvert PT. Three-dimensional gradient-echo MR imaging of the knee: comparison with arthroscopy in 100 patients. Radiology 1992;183:839-44.
28 Karvonen RL, Negendank WG, Fraser SM, Mayes MD, An $\mathrm{T}$, Fernandez-Madrid F. Articular cartilage defects of the knee: correlation between magnetic resonance imaging and gross pathology. Ann Rheum Dis 1990;49:672-5.

29 Hayes CW, Sawyer RW, Conway WF. Patellar cartilage lesions: in vitro detection and staging with $M R$ imaging and pathologic correlation. Radiology 1990;176:479-83.

30 Brown TR, Quinn SF. Evaluation of chondromalacia of the patellofemoral compartment with axial magnetic resonance imaging. Skeletal Radiol 1993;22:325-8.

31 Tervonen O, Dietz MJ, Carmichael SW, Ehman RL. MR imaging of knee hyaline cartilage: evaluation of two- and three-dimensional sequences. J Magn Reson Imaging 1993;3:663-8.

32 Broderick LS, Turner DA, Renfrew DL, Schnitzer TJ, Huff JP, Harris C. Severity of articular cartilage abnormality in patients with osteoarthritis: Evaluation with fast spin-echo MR vs arthroscopy. AJR 1994;162:99-103.

33 Peterfy CG, van Dijke CF, Janzen DL, Glüer CC, Namba R, Majumdar S, et al. Quantification of articular cartilage in the knee with pulsed saturation transfer subtraction and fat-suppressed MR imaging: Optimization and validation. Radiology 1994;192:485-91.

34 Disler DG, McCauley TR, Wirth CR, Fuchs MD. Detection of knee hyaline cartilage defects using fatsuppressed three-dimensional spoiled gradient-echo MR imaging: comparison with standard MR imaging and correlation with arthroscopy. AJR1995;165:377-82.

35 Recht MP, Pirraino DW, Paletta GA, Schils JP, Belhobek $\mathrm{GH}$. Accuracy of fat-suppressed three-dimensional spoiled gradient-echo MR imaging in the detection of patellofemoral articular cartilage abnormalities. Radiology 1996;198: 209-12.

36 Disler DG. Fat-suppressed three-dimensional spoiled gradient-recalled MR imaging: assessment of articular and physeal hyaline cartilage. AJR 1997;169:1117-23.

37 Dye SF, Boll DA. Radionuclide imaging ot the patellofemoral joint in young adults with anterior knee pain. Orthop Clin North Am 1986;17:249-62.

38 Gilbertson EMM. Development of periarticular osteophytes in experimentally induced osteoarthritis in the dog. Ann Rheum Dis 1975;34:12-24.

39 McDevitt C, Gilbertson E, Muir H. An experimental model of osteoarthritis; early morphological and biochemical changes. J Bone Joint Surg Br 1977;59:24-35.

40 Hernborg J, Nilsson BE. The relationship between osteophytes in the knee joint, osteoarthritis and aging. Acta Orthop Scand 1973;44:69-74. 